
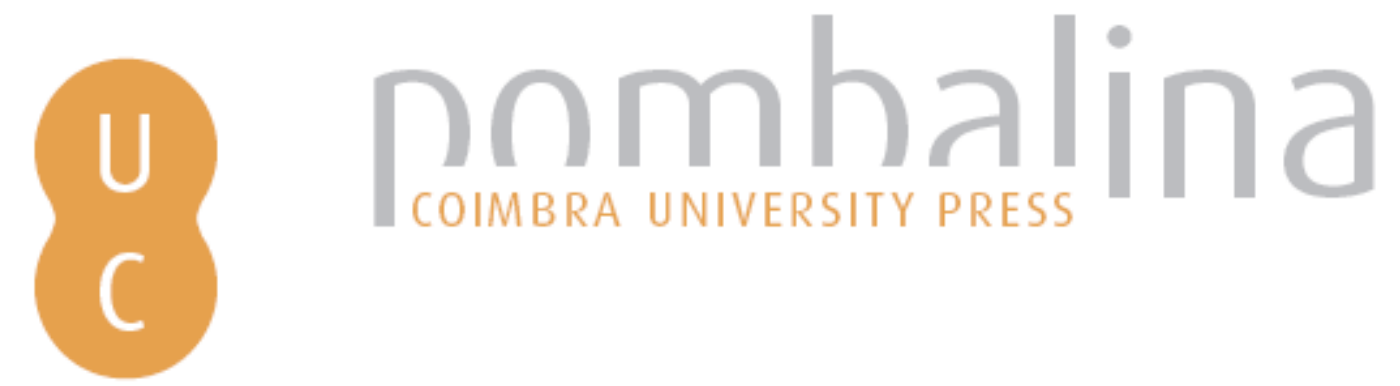

\title{
Desafios à matemática na geografia
}

Autor(es): Goodchild, Michael F.

Publicado por: Imprensa da Universidade de Coimbra; Gravida

URL

persistente:

URI:http://hdl.handle.net/10316.2/32614

DOI:

DOl:http://dx.doi.org/10.14195/978-989-26-0485-5_8

Accessed : $\quad$ 26-Apr-2023 09:21:32

A navegação consulta e descarregamento dos títulos inseridos nas Bibliotecas Digitais UC Digitalis, UC Pombalina e UC Impactum, pressupõem a aceitação plena e sem reservas dos Termos e Condições de Uso destas Bibliotecas Digitais, disponíveis em https://digitalis.uc.pt/pt-pt/termos.

Conforme exposto nos referidos Termos e Condições de Uso, o descarregamento de títulos de acesso restrito requer uma licença válida de autorização devendo o utilizador aceder ao(s) documento(s) a partir de um endereço de IP da instituição detentora da supramencionada licença.

Ao utilizador é apenas permitido o descarregamento para uso pessoal, pelo que o emprego do(s) título(s) descarregado(s) para outro fim, designadamente comercial, carece de autorização do respetivo autor ou editor da obra.

Na medida em que todas as obras da UC Digitalis se encontram protegidas pelo Código do Direito de Autor e Direitos Conexos e demais legislação aplicável, toda a cópia, parcial ou total, deste documento, nos casos em que é legalmente admitida, deverá conter ou fazer-se acompanhar por este aviso. 
(Página deixada propositadamente em branco) 
MARIA PAULA SERRA DE OLIVEIRA

Coordenadora

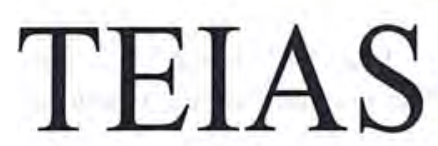

MATEMÁTICAS

Frentes na Ciência e na Sociedade 
(C) Gradiva - Publicações, L. da / Imprensa da Universidade de Coimbra, 2004 Coordenação editorial: Maria Paula Serra de Oliveira

Tradução: Artur Soares Alves

Carlota Isabel Leitão Pires Simões

Francisco José Craveiro de Carvalho

João Filipe Cortez Rodrigues Queiró

José Miguel Dordio Martinho de Almeida Urbano

Lia Sandra dos Santos

Mário da Silva Rosa

Paulo Eduardo Aragão Aleixo Neves de Oliveira

Revisão do texto: Isabel Pedrome

Capa: António Barros [Imprensa da Universidade. Coimbra], com imagem de

E. M. de Melo e Castro, "Fract 010 explod MC", Dezembro de 2003

[Fractal original gerado no Fractint com tratamento no Photoshop 7.0]

Infografia: Estúdios Estímulus [design]

Paginação: António Resende e Victor Hugo Fernandes

Impressão e acabamento: G.C. - Gráfica de Coimbra, L. da

Reservados os direitos para Portugal por:

Gradiva - Publicações, L. ${ }^{\text {da }}$ e Imprensa da Universidade de Coimbra

Gradiva - Publicações, L. ${ }^{d a}$

Rua Almeida e Sousa, 21, r/c, esq. • 1399-041 Lisboa

Telefs. $213974067 / 8 \cdot 213971357 \cdot 213953470$

Fax $213953471 \cdot$ Email: gradiva@ip.pt

URL: http://www.gradiva.pt

Imprensa da Universidade de Coimbra

Rua Antero de Quental, 195 • 3000-033 Coimbra

Telefs. 351239853110

Fax 3512398531 19 e-mail: fjrpress@ci.uc.pt

URL: http://www.imp.uc.pt

ISBN: 972-662-970-5

1." edição: Maio de 2004

Depósito legal n. ${ }^{\circ} 210431 / 04$

OBRA PUBLICADA COM O PATROCÍNIO DE:

CENTRO DE MATEMÁTICA DA UNIVERSIDADE DE COIMBRA DEPARTAMENTO DE MATEMÁTICA DA UNIVERSIDADE DE COIMBRA

FCT Fundação para a Ciência e a Tecnologia

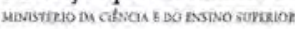


Michael F. Goodchild

Universidade da Califórnia

Santa Bárbara, EUA

\section{Desafios à matemática na geografia ${ }^{1}$}

\section{INTRODUÇãO}

A ciência matemática e a geografia têm usufruído de uma longa e frutuosa associação, desde que despertou o interesse inicial da humanidade por medir a Terra até à actual e crescente dependência dos sistemas informáticos para o estudo da geometria, da topologia e das propriedades estatísticas da informação sobre a superfície da Terra. A matemática ajudou a resolver no passado, no âmbito da geografia, muitos problemas importantes, como, por exemplo, o da descrição eficiente da forma complexa da Terra como pré-requisito da cartografia exacta, continuando a ser um instrumento imprescindível para os geógrafos na sua busca contínua de um melhor conhecimento da Terra como o lar da humanidade.

Neste artigo será feita uma breve súmula da associação entre a matemática e a geografia, desde o tempo das primitivas comunidade recolectoras até à complexa sociedade actual, baseada na informação. Em seguida serão discutidos quatro exemplos específicos do modo como a matemática constitui um instrumento fundamental na geografia moderna. Ao fazê-lo, espero contribuir com indicações inegáveis de que a interacção entre a matemática e a geografia tem um passado ilustre, um presente interessante e um futuro excitante.

1 Tradução de Artur Soares Alves, professor do Departamento de Matemática, Universidade de Coimbra. 


\section{RESUMO HISTÓRICO}

A ideia de criar uma representação abstracta do meio circundante é mais antiga do que a própria humanidade. Sabe-se que as abelhas comunicam informações sobre a localização dos recursos alimentares dançando umas para as outras; uma comunicação muito mais sofisticada tornou-se possível quando os humanos desenvolveram a linguagem e as aptidões necessárias para traçar representações sob a forma de mapas primitivos nas paredes das cavernas e na poeira do chão. Os primeiros navegadores do Pacífico utilizavam composições adequadas de paus para trocar informações e para transmitir esse conhecimento às gerações mais novas. Porém, a emergência da agricultura sedentária, há cerca de dez mil anos, e as sociedades complexas que com ela evoluíram criaram a necessidade não somente de representar a Terra mas também de a medir. A geometria (literalmente medida da Terra) evoluiu, de certo modo, como resposta à necessidade de registar a propriedade e a produtividade da terra e também para permitir a construção de estruturas permanentes de abrigo, de armazenamento do grão e para satisfazer outros fins comunais.

A agricultura e a construção são, comparativamente, actividades com um âmbito local, mas o comércio entre comunidades humanas situadas a longas distâncias, por mar ou por terra, estimulou o interesse pela navegação e pela relação entre a Terra e os outros corpos celestes. Desenvolveram-se métodos para registar e medir as superfícies curvas e, por volta de 200 a.C., Eratóstenes deduziu o raio de curvatura da Terra comparando a elevação do Sol acima do horizonte ao meio-dia em dois lugares situados a uma distância conhecida e sobre o mesmo meridiano.

$\mathrm{O}$ avanço do cristianismo e da sua doutrina ajudou ou prejudicou, dependendo do ponto de vista, a evolução da descrição matemática da Terra. A crença de que Deus criara uma Terra perfeita conduziu à representação de um universo geocêntrico e aos antigos mapas que representavam a região mediterrânica com uma forma geométrica perfeita, com Jerusalém, centro da cristandade, em posição de destaque. Os conhecimentos resultantes dos descobrimentos portugueses, no início do século $\mathrm{XV}$, eram claramente incompatíveis com estas crenças, porém, foi só no século XVII que o peso da evidência empírica se sobrepôs finalmente à doutrina cristã, abrindo o caminho para a Idade das Luzes (só recentemente a Igreja admitiu o seu erro em perseguir Galileu por causa da sua oposição, cientificamente fundamentada, ao universo geocêntrico).

A invenção da imprensa criou um dos mais antigos desafios matemáticos propostos pela geografia. Todos os sistemas que se desenvolveram em torno da imprensa para disseminar o conhecimento 
humano - papel, livros, atlas, cartas, envelopes - são planos, mas a superfície da Terra é curva. Por isso, qualquer representação da Terra à escala, a duas dimensões, como por exemplo um mapa, terá de ser distorcida, aumentando o grau de distorção com a proporção da superfície da Terra representada. Ainda hoje, a ciência das projecções cartográficas continua a levantar uma série de problemas estimulantes para os matemáticos. São necessárias novas projecções para se obter um conhecimento e uma representação cada vez mais precisos da forma da Terra e para servir de suporte às necessidades particulares de novas aplicações.

O século XVIII trouxe consigo um novo interesse pela representação precisa da forma detalhada da superfície da Terra. A construção de canais tornava necessário fazer nivelamentos precisos e a artilharia requeria $\mathrm{o}$ conhecimento exacto da altura relativa. A noção do uso de contornos, ou curvas de nível, para mostrar a forma em pormenor surgiu nesta altura, associada em primeiro lugar à batimetria ou representação da profundidade das águas. A elevação acima do nível do mar não é medida com a mesma facilidade que a profundidade abaixo do nível do mar e, assim, decorreu algum tempo até que esses métodos pudessem ser aplicados na elaboração de mapas rigorosos de curvas de nível para a elevação do terreno.

Um dos primeiros mapas deste tipo foi elaborado em meados do século XVIII com o objectivo de levar a cabo uma experiência, proposta por Sir Isaac Newton certa de 100 anos antes, para estimar a densidade da Terra. Schiehallion é uma montanha relativamente isolada, aproximadamente cónica, na Escócia. Em 1774 uma equipa de topógrafos criou um mapa exacto de curvas de nível e, a partir daí, calculou uma estimativa do volume da montanha. Medições precisas da direcção e grandeza da força gravitacional da Terra foram então efectuadas para obter a densidade desconhecida.

As Descobertas iniciadas por Portugal no século XV criaram a necessidade de uma cartografia exacta, a que os matemáticos responderam com métodos que permitiam determinar a posição com extrema precisão. Todos esses métodos requeriam um modelo matemático básico da forma da Terra e, embora uma esfera seja suficientemente exacta para muitos objectivos, um elipsóide (obtido por rotação de uma elipse em torno do eixo menor) constitui uma representação muito mais precisa da Terra porque esta é ligeiramente achatada ao longo do seu eixo, por um factor de cerca de 1/300. Em meados do século XX, várias medições rigorosas em diferentes partes da Terra deram origem a uma grande variedade de elipsóides, cada um deles destinado a ajustar-se melhor a um determinado 
sector geográfico (ou administrativo). A tabela 1 mostra alguns dos mais importantes elipsóides e os respectivos parâmetros associados. Mesmo actualmente, os mapas produzidos por países adjacentes não se ajustam necessariamente ao longo da sua fronteira comum, a menos que estes países utilizem o mesmo elipsóide e a mesma projecção. A Guerra Fria e a necessidade de guiar com precisão os mísseis intercontinentais levou finalmente à adopção, na segunda metade do século XX, de um elipsóide padrão internacional.

Tabela 1 -Alguns elipsóides importantes de referência (o WGS84 tornou-se o elipsóide mais importante usado internacionalmente).

\begin{tabular}{lll}
\hline Elipsóide & Semi-eixo maior $(\mathrm{m})$ & 1/achatamento \\
\hline Airy 1830 & 6377563.396 & 299.3249646 \\
Modified Airy & 6377340.189 & 299.3249646 \\
Australian National & 6378160 & 298.25 \\
Bessel 1841 (Namibia) & 6377483.865 & 299.1528128 \\
Bessel 1841 & 6377397.155 & 299.1528128 \\
Clarke 1866 & 6378206.4 & 294.9786982 \\
Clarke 1880 & 6378249.145 & 293.465 \\
Everest (India 1830) & 6377276.345 & 300.8017 \\
Everest (Sabah and Sarawak) & 6377298.556 & 300.8017 \\
Everest (India 1956) & 6377301.243 & 300.8017 \\
Everest (Malaysia 1969) & 6377295.664 & 300.8017 \\
Everest (Malaysia and Singapore) & 6377304.063 & 300.8017 \\
Everest (Pakistan) & 6377309.613 & 300.8017 \\
Modified Fischer 1960 & 6378155 & 298.3 \\
Helmert 1906 & 6378200 & 298.3 \\
Hough 1960 & 6378270 & 297 \\
Indonesian 1974 & 6378160 & 298.247 \\
International 1924 & 6378388 & 297 \\
Krassovsky 1940 & 6378245 & 298.3 \\
GRS 80 & 6378137 & 298.257222101 \\
South American 1969 & 6378160 & 298.25 \\
WGS 72 & 6378135 & 298.26 \\
WGS 84 & 6378137 & 298.257223563 \\
\hline
\end{tabular}

Nos últimos trezentos anos, a geodesia, ou medição exacta da forma da Terra e respectivas propriedades, juntamente com a cartografia, concluíram praticamente o projecto que os estudiosos iniciaram há mais de dois milénios. Hoje em dia conhecemos a forma e as propriedades gravitacionais da Terra com exactidão suficiente para medir mudanças milimétricas na posição dos continentes; possuímos métodos bastante desenvolvidos para cartografar a superfície de outros planetas, incluindo asteróides de forma não-esférica e luas longínquas; existe ainda o Sistema 
de Posicionamento Global (GPS), uma constelação de satélites artificiais da Terra que, pela primeira vez na história da Humanidade, permite a medição exacta da posição à superfície terrestre relativamente a um sistema de coordenadas geocêntricas. As imagens obtidas pelos satélites em torno da órbita da Terra podem ser processadas utilizando sofisticados algoritmos informáticos para uma rápida actualização dos mapas. As bases de dados geográficos contêm quantidades enormes de informação sobre as características da superfície terrestre e são, em muitos casos, acessíveis de qualquer lugar, via Internet. Os modelos matemáticos são utilizados rotineiramente para prever os movimentos da atmosfera e dos oceanos, para analisar fluxos comerciais, tráfego rodoviário, chamadas telefónicas, idas às compras e para examinar padrões de doenças. A matemática e a geografia estão agora intimamente ligadas e mais do que nunca através da tecnologia da informação.

As próximas quatro secções abordam áreas onde a matemática e a geografia interagem de um modo particularmente estimulante e interessante. $\mathrm{O}$ conjunto é de facto muito pessoal, reflectindo os meus próprios interesses e gostos, assim como experiências acumuladas nas últimas três décadas.

\section{PROPRIEDADES TOPOLÓGICAS DAS BACIAS HIDROGRÁFICAS E DOS POVOAMENTOS}

A superfície da Terra é inacreditavelmente complexa. Suponhamos que se quer examiná-la globalmente e analisar características tão pequenas como as que medem cerca de um metro. Há aproximadamente 500000000 quilómetros quadrados de superfície e, se atribuíssemos um único carácter ( 1 byte) à representação de cada metro quadrado, a base de dados resultante teria um tamanho da ordem de um petabyte $\left(1\right.$ petabyte $=10^{15}$ bytes; esta estimativa pressupõe a não compressão dos dados). Se se digitalizarem estes dados, preenchendo um ecrã de computador com dados novos a cada segundo que passa (cerca de um quilómetro quadrado por segundo para a resolução de um ecrã típico), digitalizar toda a Terra demoraria a vida inteira de um ser humano. É assim extremamente importante encontrar representações compactas e eficientes das características significativas para aplicações específicas.

Em 1945, o geomorfologista Horton ficou intrigado com os complexos padrões formados na superfície terrestre pelas redes de cursos de água ou bacias hidrográficas. Seriam essas redes de canais tão complexas como pareciam ou apresentariam algumas simetrias e padrões básicos? Seriam 
determinadas representações dos cursos de água mais adequadas do que outras para revelar essas simetrias e padrões? Os detalhes geométricos dos cursos de água pareciam relativamente pouco importantes, mas seria provável que as propriedades topológicas - noutras palavras, as propriedades que se mantêm quando as propriedades geométricas são alteradas por estiramento ou distorção - pudessem revelar padrões interessantes. Horton concebeu um método de numeração dos cursos de água de uma bacia hidrográfica para identificar as suas propriedades topológicas baseando-se na suposição de que uma rede de cursos de água é um grafo em árvore (não contém circuitos). O método, na forma mais tarde modificada por Strahler (1952), está indicado na figura 1. Os cursos de água mais pequenos foram assinalados primeiro com um «1». Qualquer curso de água resultante da junção de dois «1» é assinalado com um «2». De um modo semelhante, juntando-se dois « 2 » forma-se um novo « 3 » e, geralmente, a junção de dois cursos de água de ordem $i$ produz um novo curso de ordem $i+1$ (a junção de um curso de ordem $i$ e de um curso de água de ordem menor do que $i$ não produz um novo curso de água).

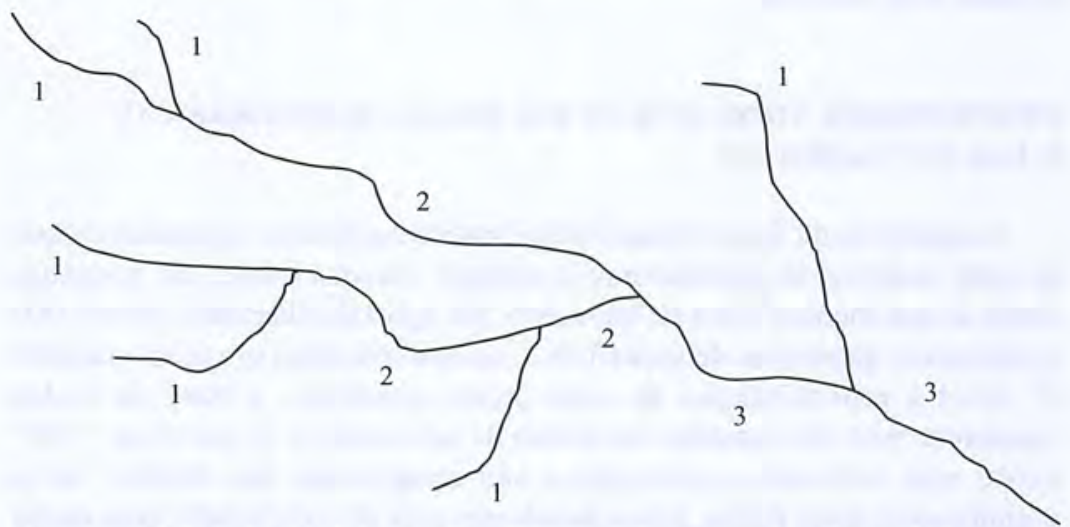

Fig. 1 -O sistema de Horton para numerar as caracteristicas topológicas de redes de água, modificado por Strahler

Ao simplificar as bacias hidrográficas deste modo, Horton descobriu algumas regularidades empíricas notáveis (Horton, 1945). A Law of Stream Numbers foi constatada contando os números de cursos de cada ordem e assinalando-os num gráfico de dispersão e colocando o logaritmo do número em contraste com o número de ordem. Na maioria dos casos, o gráfico mostrou-se, de um modo notável, ajustado a uma linha recta. 
Por outras palavras, a relação entre o número de cursos de uma dada ordem $i, N(i)$, e o número de cursos da ordem mais alta seguinte, $N(i+1)$, revelou-se uma constante. Em geral, $N(i) / N(i+1)=B$, sendo $B$ uma constante designada por taxa de bifurcação e apresentando um valor de aproximadamente 4,5 para muitas redes de cursos de água. Horton tinha encontrado o que parecia ser uma forte regularidade, facto este que suscitou a busca de uma teoria explicativa apropriada.

Quando duas variáveis são consideradas num gráfico de dispersão é frequentemente utilizada uma linha recta como indicador de uma forte relação, ao passo que duas variáveis que não estão relacionadas produzem uma nuvem dispersa de pontos. Mas os gráficos de Horton não são gráficos de dispersão normais. Tendo em conta o modo como as duas variáveis são definidas, o gráfico nunca poderá resultar numa nuvem de pontos, pois nenhum $N(i+1)$ é superior a $N(i) / 2$. Num artigo publicado em 1966 (Shreve, 1966; ver também Shreve, 1967; Abrahams, 1984), cerca de vinte anos depois do trabalho original de Horton, Shreve formulou a pergunta óbvia: como seria a topologia de uma rede «aleatória» de cursos de água que não sofresse qualquer influência das leis físicas e não apresentasse nenhum dos padrões observados por Horton?

Shreve sugeriu que uma definição razoável de «aleatório», neste caso, seria todas as possíveis topologias de redes, com um dado número de cursos de água de primeira ordem, terem a mesma probabilidade. A figura 2 mostra as 14 redes teoricamente possíveis e topologicamente distintas sendo $N(1)=5$; presumivelmente as forças da natureza tornam algumas delas impossíveis ou menos prováveis que outras, e este facto conduz à aparente regularidade de Horton. No entanto, através da análise matemática, Shreve conseguiu mostrar que a lei de Horton seria também verdadeira para estas hipotéticas redes de canais se estas ocorressem com igual probabilidade - por outras palavras, a lei era uma simples consequência do acaso estatístico, e não de um processo físico influenciando as probabilidades. Os efeitos dos processos físicos revelavam-se melhor em certos desvios da linha recta de Horton do que na própria linha.

As bacias hidrográficas são um exemplo de um fenómeno físico e os cursos de água que Horton estudou não apresentavam praticamente nenhuma modificação introduzida pelo homem. Mas os geógrafos também estudam os padrões formados na superfície terrestre pela actividade humana e questionam-se do mesmo modo sobre a existência de padrões e regularidades. Um dos padrões mais impressionantes é o formado pelas povoações - aldeias, vilas e cidades. A sua localização é muitas vezes determinada pelas características do terreno, tal como as linhas costeiras, as margens e os rios, mas, em alguns casos, principalmente nas planícies 
da América do Norte, Europa ou Ásia, as povoações podem localizar-se praticamente em qualquer lugar.
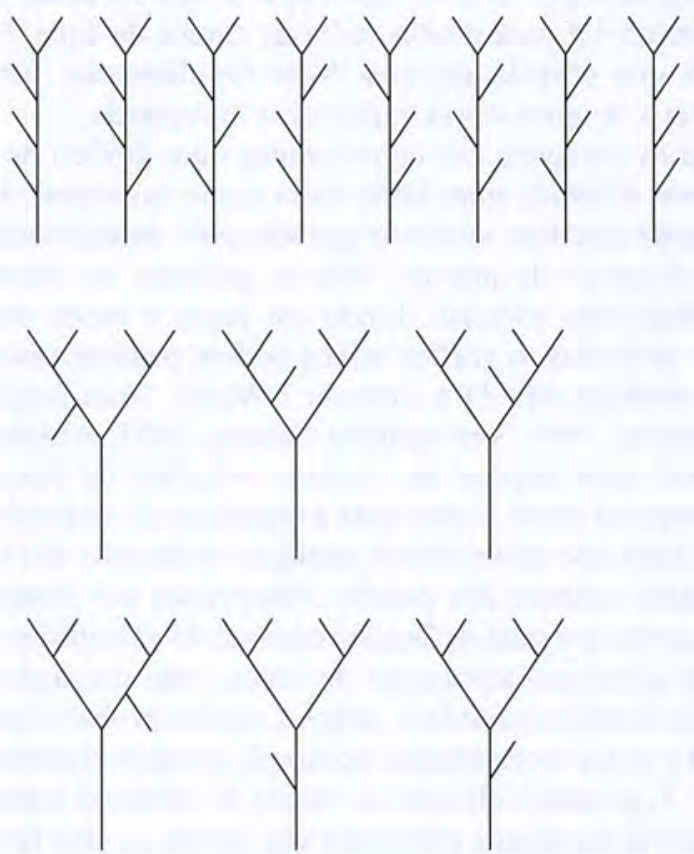

Fig. 2-As catorze redes de canais topologicamente distintos que se podem formar a partir de cinco cursos de água de primeira ordem. Oito têm um curso de água de segunda ordem; as restantes seis possuem dois de segunda ordem e um de terceira ordem

Em 1933, o geógrafo Christaller propôs uma teoria das povoações, ou locais centrais, baseada em princípios simples de comportamento económico (Christaller, 1966). O nível mais baixo de povoamento, uma aldeia, fornece os serviços mais simples, como por exemplo, a mercearia; os serviços mais complexos, como os centros comerciais, só estão disponíveis nas povoações maiores. Os investidores de grandes armazéns procuram maximizar o rendimento ou o investimento e tentam estabelecer-se nos sítios mais lucrativos. Sob certos pressupostos, a competição resultará em agrupamentos regulares de povoações na paisagem, em que cada ordem, desde a mais baixa, irá ocupar um nó numa grelha hexagonal. As povoações de ordem mais alta também irão formar uma grelha 
hexagonal com uma menor densidade, em co-localização com os centros de ordem mais baixa. Os números de centros em cada nível estarão fixados numa razão fixa igual a $3,4,7$ ou a produtos destes números inteiros.

A lei de Horton surgiu a partir da observação, tendo-se depois partido para o estabelecimento da teoria. Christaller desenvolveu primeiro a teoria, procurando posteriormente a sua validação empírica. Seria possível comprovar, particularmente em áreas de povoamento denso em planície, os padrões teóricos previstos por esta teoria? E, mesmo que não se encontrassem padrões perfeitamente hexagonais, haveria, ainda assim, vestígios de perfeição? Um vasto número de estudos acerca deste problema surgiu então nos anos 50 e 60 .

Um dos mais interessantes dependia da possibilidade de identificar a área de influência de cada povoação. Suponha-se que cada povoação formava o centro de uma unidade administrativa, tal como um distrito (para comunidades maiores) ou uma freguesia. A unidade poderia não ser um hexágono geométrico, mas teria talvez algumas das propriedades topológicas dos hexágonos, por exemplo, talvez houvesse uma tendência para que cada unidade tivesse seis vizinhos. Identificaram-se áreas adequadas, onde as condições favoreciam a teoria de Christaller e onde as unidades administrativas foram devidamente definidas e cartografadas, tendo os estudos nestas áreas encontrado um número médio de vizinhos muito próximo de seis.

Mas embora a intuição nos diga que uma média de 5,91 é uma notável aproximação de 6 , tal como no caso de Horton, falta-nos uma base racional para a avaliação. Que média se obteria a partir de uma configuração aleatória de unidades que não tivessem sido influenciadas pelas forças económicas admitidas por Christaller? Neste caso uma simples taça de poliuretano forneceria a resposta. As bolhas de poliuretano são geradas por processos que estão longe de ser análogos aos processos económicos que operam na paisagem humana, mas, curiosamente, uma simples análise mostra que também elas têm um número médio de vizinhos muito próximo dos 6 .

A teoria subjacente a esta problemática é uma lei descoberta por Euler. Se se tomar uma pavimentação (divisão de um plano em áreas), os números de áreas $A$, de arestas entre elas $E$, e de vértices onde se tocam as arestas $N$, devem satisfazer a expressão $A-E+N=1$. Definindo as regras apropriadas de modo a identificar ou contar objectos, a lei de Euler citada conduz directamente ao resultado observado, notando-se, embora, que o número médio de vizinhos é inferior a 6 porque as arestas partilhadas pelas áreas adjacentes são contadas duas vezes, ao passo que as arestas que circundam o mosaico são contadas uma vez. 
Estes dois exemplos demonstram um dos princípios básicos da análise geográfica. Sabemos que os olhos e o cérebro podem ser facilmente enganados pela aparência do padrão, e muitas ilusões ópticas atestam isto mesmo. Têm-se encontrado padrões e formas na disposição aleatória das estrelas no céu nocturno ou nas variações da superfície de Marte. Mas uma análise matemática cuidadosa mostrou, em muitos destes casos, que o que parecem ser padrões sistemáticos não são mais do que acontecimentos ao acaso no espaço, uma vez que se encontrem e implementem definições apropriadas de acaso. O ser humano parece não estar, de um modo geral, suficientemente equipado para discriminar os padrões das características aleatórias no espaço.

\section{GEOESTATÍSTICA, FRACTAIS E DEPENDÊNCIA ESPACIAL}

Qualquer estudante de Estatística conhece o conceito de independência - a noção de que acontecimentos sucessivos não têm memória de outros acontecimentos passados. Uma moeda, por exemplo, não tem memória do seu comportamento passado e o resultado de um lançamento não influencia o seguinte. A independência é um pressuposto razoável em muitas experiências e é a base de muitos testes típicos de estatística.

Mas tudo é diferente na superfície terrestre. O geógrafo Waldo Tobler exprimiu esta diferença do seguinte modo: «Tudo está relacionado, mas as coisas próximas estão mais relacionadas do que as distantes». Por outras palavras, a independência quase nunca é um pressuposto válido para acontecimentos que ocorrem à superfície da Terra, excepto quando esses acontecimentos são muito longínquos entre si. Por exemplo, considere-se o fenómeno da temperatura do ar, que varia com o local como uma função $T(x)$, onde $T$ representa a temperatura e $x$ a posição. Suponhamos que se conhece a temperatura em $x$ e que temos de estimá-la noutro local, $y$ (talvez porque se pretenda viajar até lá). Quando $x$ e $y$ estão muito próximos, $T(x)$ é uma estimativa muito segura de $T(y)$ porque a temperatura na superfície da Terra só se altera rapidamente em circunstâncias especiais, como, por exemplo, durante a passagem de frentes climáticas ou na proximidade de águas frias. Quanto mais afastado $y$ estiver de $x$, menos exacto será $T(x)$ como estimativa de $T(y)$.

A observação de Tobler é suficientemente genérica para lhe poder ser conferido o estatuto de lei. Têm sido concebidas várias medidas de dependência espacial e o termo geral para as designar é autocorrelação espacial. A lei de Tobler estabelece, na sua essência, que a autocorrelação 
espacial é fortemente positiva para distâncias curtas e enfraquece com a distância. Existem vários termos para designar a distância à qual a autocorrelação espacial decresce para zero, como por exemplo range e grain. A autocorrelação espacial negativa ocorre quando a diferença entre fenómenos a uma dada distância é maior do que a variação global (um tabuleiro de xadrez é um bom exemplo), mas a autocorrelação espacial negativa entre algumas distâncias deve implicar a autocorrelação espacial positiva entre outras distâncias. De facto, um mundo sem autocorrelação espacial seria quase impossível de imaginar ou habitar. Cada alteração microscópica de posição produziria tanta variação como a que existe no mundo como um todo e a vida seria como estar a cair constantemente de uma falésia.

Um dos modos mais eficazes de representar a dependência espacial é através da função que os geoestatísticos designam por variograma. $\mathrm{Na}$ figura 3, cada ponto denota um par de localizações. O valor marcado no eixo horizontal é a distância entre elas e o valor no eixo vertical é o quadrado da diferença dos valores em causa. Neste exemplo, no eixo vertical assinalam-se os quadrados das diferenças das temperaturas. As barras verticais denotam intervalos convenientes do eixo horizontal. Calcula-se a média dos pontos dentro de cada intervalo para se marcarem as pintas. Finalmente ajusta-se a estas pintas uma curva regular que representa uma função pertencente a um conjunto padrão de funções matemáticas. Esta curva é o variograma, denotado pela função $2 \gamma(d)$, onde $d$ representa a distância. Geralmente constata-se que os variogramas, para fenómenos na superfície da Terra, têm uma forma notavelmente consistente, como se ilustra na figura caracterizada por um crescimento monótono seguido por uma atenuação no domínio onde a variância já não aumenta.

Esta observação tem sido muito útil no tratamento da informação geográfica. Uma aplicação frequente ocorre quando um fenómeno foi sujeito a amostragem num determinado número de locais, como acontece, por exemplo, na amostragem de fenómenos climáticos, como a temperatura, a precipitação ou a pressão atmosférica. Razões monetárias impedem que estes fenómenos possam ser medidos em qualquer local. Assim, em locais onde não são efectuadas medições procede-se a estimativas explorando a lei de Tobler e as propriedades específicas do variograma. $\mathrm{O}$ método espacial de interpolação designado por Kriging foi inventado por um geólogo, nos anos 50, para implementar este conceito. Noutras disciplinas foram inventados métodos muito semelhantes. A área da geoestatística baseia-se nestes métodos. 
Metade da média do quadrado das diferenças (semivariância)

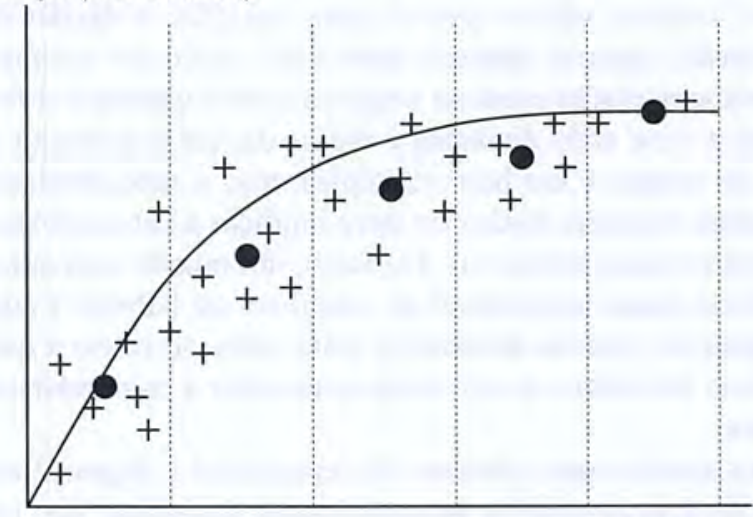

Distância

Fig. 3-Um semivariograma típico. Os símbolos são explicados no texto

Mas a correlação espacial não é a única propriedade matemática dominante dos dados geográficos. Quem já trabalhou exaustivamente com dados geográficos refere os efeitos da complexidade e, particularmente, da relação entre complexidade e resolução espacial: quanto mais de perto se olha a geografia mais pormenores se vêem. As linhas costeiras mostram claramente esta propriedade, tornando-se cada vez mais sinuosas num exame próximo e, consequentemente, também mais extensas. Nenhum geógrafo leva a sério os debates sobre a extensão da orla costeira ou sobre a extensão das fronteiras políticas, sabendo estes que é possível produzir uma larga variedade de extensões dependendo da escala do exame a efectuar. Por exemplo, em 18 de Novembro de 2000, o Seattle Times noticiou um novo cálculo do comprimento da costa da Noruega. A nova estimativa, calculada a partir de uma representação digital detalhada, tinha mais 13760 milhas que a extensão anteriormente estimada em 35580 milhas. O objectivo desta notícia era corrigir um erro, mas para os geógrafos tratava-se do simples resultado de um exame mais pormenorizado da linha costeira.

Benoît Mandelbrot foi o primeiro a dar a estas observações um enquadramento matemático formal, a que deu o nome de fractais ou fenómenos geométricos que exibem dimensões fraccionárias (Mandelbrot, 1983). As propriedades fractais podem ser associadas a pontos, linhas, áreas ou superfícies, e muitos dos exemplos que Mandelbrot utilizou nos 
seus livros eram de natureza geográfica. Os fractais mostram propriedades de auto-semelhança, o que significa que uma parte do objecto tem propriedades, tais como a forma geométrica, que são verdadeiras para o objecto considerado como um todo. Um corolário interessante desta propriedade é a impossibilidade de determinar a escala de um objecto fractal, dado que se pode estar a olhar para uma parte de um tamanho qualquer. As propriedades dos fractais comportam-se sistematicamente como mudanças de escala, fornecendo um dos poucos enquadramentos teóricos que permitem estudar o efeito da escala. Por exemplo, o comprimento de uma linha fractal altera-se consoante o nível de detalhe a que é mostrada e medida, numa relação simples do tipo potência. Este comportamento tinha sido observado anteriormente por Richardson no seu estudo sobre as extensões das fronteiras políticas (Richardson, 1961), mas os fractais de Mandelbrot são os primeiros a fornecer uma explicação teórica da questão. Goodchild e Mark (1987) apresentam uma visão geral da importância dos fractais na geografia.

Os fractais têm variogramas bem comportados, não admitindo, no entanto, tangentes - comportamento que conduziu à utilização do termo monstro matemático para descrever os fractais, o que aliás acontece na representação gráfica de muitos fenómenos geográficos. O relevo da superfície da Terra é muitas vezes concebido como uma função matemática de posição, $z=z(x)$, e em muitos estudos utilizaram-se funções típicas, tais como polinómios ou séries de Fourier, para descrever partes da superfície. Contudo, também é verdade que a superfície da Terra mostra frequentemente falésias, cumeeiras, canais e outros fenómenos que representam descontinuidades na elevação ou no declive.

Por outras palavras, a função $z$ não é contínua e diferenciável em todo o lado e, logo, as suas tangentes não estão bem definidas em todo o lado. Embora recorramos com frequência a metáforas de terreno quando se fala de funções matemáticas (por exemplo, superficie, elevação, gradiente), há sem dúvida fortes razões para o facto de ser falacioso pensar no terreno como tendo uma forma matemática perfeita. É interessante especular sobre a importância da metáfora terreno para os iniciadores do cálculo (Newton e Leibniz) e interrogarmo-nos sobre se os terrenos que lhes eram familiares eram particularmente livres de descontinuidades.

Uma consequência deste problema é que, à semelhança do que acontece no exemplo do comprimento da linha costeira discutido anteriormente, o declive da superfície da Terra não pode ser definido independentemente da resolução espacial. Na prática, o declive é definido através 
de uma aproximação de diferenças finitas, utilizando tipicamente as seguintes equações:

$$
\begin{aligned}
& b=\left(\mathrm{z}_{3}+2 \mathrm{z}_{6}+\mathrm{z}_{9}-\mathrm{z}_{1}-2 \mathrm{z}_{4}-\mathrm{z}_{7}\right) / 8 \mathrm{D} \\
& c=\left(\mathrm{z}_{1}+2 \mathrm{z}_{2}+\mathrm{z}_{3}-\mathrm{z}_{7}-2 \mathrm{z}_{8}-\mathrm{z}_{9}\right) / 8 \mathrm{D}
\end{aligned}
$$

onde $b$ e $c$ representam declives das tangentes respectivamente nas direcções $x$ e $y, D$ é o espaçamento da grelha e $z_{i}$ denota a cota do ponto $i$, como se mostra na figura 4 . A ausência de tangentes bem definidas à superfície da Terra obriga a que as estimativas de $b$ e $c$ dependam explicitamente de $D$. Por exemplo, os declives calculados a partir de uma grelha com espaçamento de 30 metros são diferentes dos declives na mesma localização calculados a partir de uma grelha com espaçamento de 100 metros (existem vários conjuntos de dados com aproximadamente estes dois espaçamentos para a maior parte dos EUA).

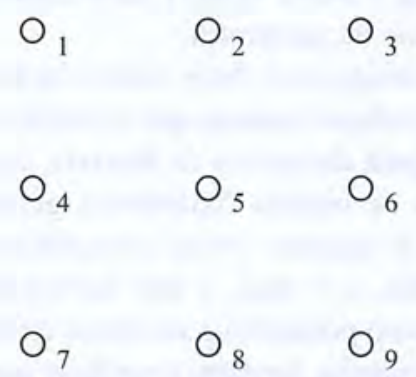

Fig. 4-Notação utilizada na estimação do declive

Os fractais mostraram-se muito úteis na ciência da informação geográfica. Primeiro, como foi dito anteriormente, fornecem um enquadramento teórico para o estudo dos efeitos da escala, permitindo-nos antever até que ponto se ganham ou perdem detalhes quando a resolução espacial se altera e determinar os benefícios e os custos do aumento da resolução quando se projectam satélites para obter imagens da superfície da Terra. As curvas fractais descritas por Peano e Hilbert (figura 5) constituem também uma base para estruturas de dados eficientes e para a concepção de ordenações unidimensionais do espaço que procuram preservar relações espaciais bidimensionais. Estas ideias são implementadas em muitos dos actuais sistemas de informação geográfica. Nos últimos anos os investigadores têm vindo a estudar a forma como estes conceitos se podem aplicar à superfície curva da Terra. 

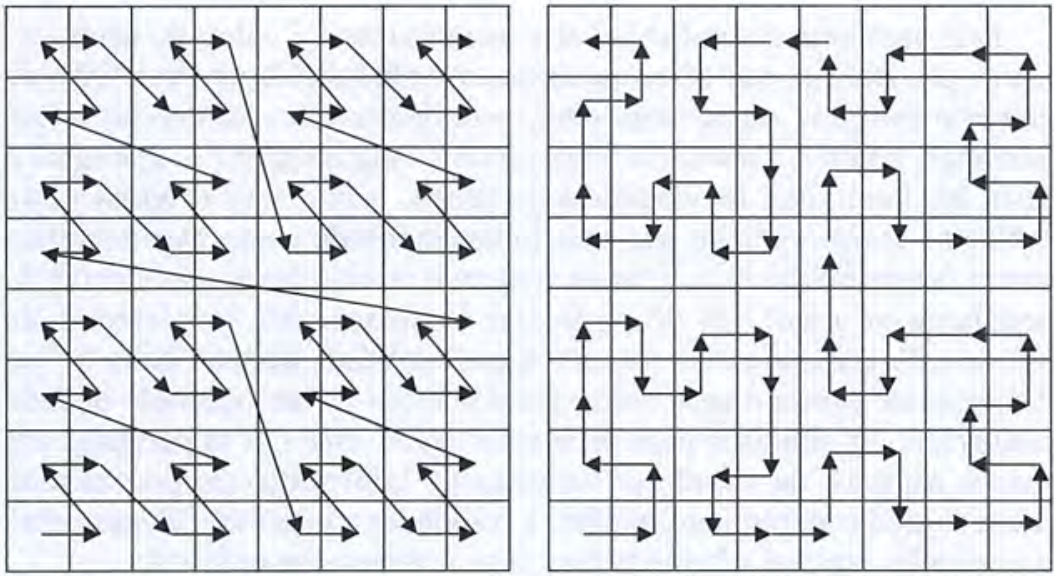

Fig. 5-As curvas de Peano e Hilbert que preenchem o espaço têm sido implementadas em sistemas de informação geográfica como base de técnicas de compressão de dados e esquemas de indexação

\section{Probabilidade geométrica}

A probabilidade geométrica é um ramo da matemática que se dedica ao estudo de inferências estatísticas dos acontecimentos geométricos. Tem sido uma fonte de problemas estimulantes e mesmo de diversão para os matemáticos. Recentemente, surgiu uma nova série de desafios relacionados com o interesse em prever o desempenho dos sistemas de informação geográfica. Muitos dos processos actualmente aplicados aos dados geográficos têm resultados variáveis, dependendo da frequência com que ocorrem determinadas condições extremas ou patológicas. Por exemplo, considere-se o problema do cálculo da distância entre dois pontos na superfície terrestre. A projecção Universal Transverse Mercator (UTM) é vulgarmente utilizada como base das coordenadas em sistemas de informação geográfica e foi adoptada como padrão militar internacional pela NATO. A projecção UTM divide a Terra em faixas ou zonas com amplitude de seis graus de longitude. Se dois pontos se situarem na mesma zona, então a distância entre eles pode ser calculada a partir das suas coordenadas UTM e de uma expressão simples do teorema de Pitágoras, com um erro máximo de $0,04 \%$. Mas, se os dois pontos se situarem em zonas UTM diferentes, têm de ser efectuados cálculos muito mais complexos e morosos. O desempenho depende assim directamente da probabilidade de qualquer par de pontos se situar na mesma zona. 
Este problema de probabilidades geométricas foi colocado primeiramente por Buffon, que determinou que a probabilidade de uma linha de comprimento $l$ se cruzar com uma recta dentre um conjunto de rectas paralelas, sendo $a$ a distância entre rectas contíguas $\operatorname{com} l<a$, é igual a $2 l /(\pi a)$. Para além da elegância da prova, o interesse original neste problema reside também nas suas potencialidades como base empírica para a determinação de p. Têm-se analisado muitos desenvolvimentos do problema original; um de particular interesse para os sistemas de informação geográfica diz respeito à probabilidade de uma linha de um determinado comprimento cruzar um dos lados de um quadrado de lado conhecido. As soluções para problemas como este são importantes em muitos aspectos da criação de sistemas de informação geográfica e de bases de dados porque nos ajudam a responder a questões básicas sobre a resolução espacial adequada para uma determinada aplicação.

\section{OPTIMIZAÇÃo ESPACIAL}

A última destas quatro secções aborda uma classe de problemas que desde sempre me intrigaram, em parte por causa da sua complexidade e em parte por causa da natureza não intuitiva de muitas das suas soluções. Trata-se de problemas de optimização espacial ou de busca de soluções óptimas para problemas colocados no espaço tridimensional. Um dos mais conhecidos é o problema do caixeiro viajante (traveling salesman problem - TSP), ou seja, o problema de seleccionar o melhor caminho para visitar um determinado número de destinos numa só viagem, a partir de um dado ponto. Se houver $n$ destinos, incluindo o ponto de partida, o número possível de viagens é $(n-1) ! / 2$ (o factor 2 entra porque qualquer viagem pode ser executada nos dois sentidos). Este número cresce muito rapidamente com $n$ e, consequentemente, o problema TSP não pode ser resolvido em tempo razoável a não ser para valores pequenos de $n$.

Apesar da sua complexidade inerente, estes problemas são agora rotineiramente resolvidos através de métodos heurísticos, métodos de solução que se espera possam vir a oferecer soluções satisfatoriamente próximas da óptima. Dado um par de pontos identificados pelas suas direcções, qualquer utilizador da Internet pode contactar um certo número de sites (incluindo www.mapquest.com) e obter a solução para o problema do caminho mais curto, ou o trajecto óptimo entre os dois pontos através da teia de ruas. Milhões de pessoas acedem a estes sites todos os dias para planearem as férias ou viagens de negócios em áreas que lhes são desconhecidas. 
Considere-se um conjunto de pontos distribuídos num plano, cada um com coordenadas $\left(x_{i}, y_{i}\right)$ e com pesos $w_{i}$. Se estes pesos representarem contagem de pessoas, será útil saber a localização $(X, Y)$ que minimiza a distância total percorrida, por outras palavras, o ponto que minimiza:

$$
Z=\Sigma_{i} w_{i}\left[\left(x_{i}-X\right)^{2}+\left(y_{i}-Y\right)^{2}\right]^{1 / 2}
$$

Este ponto tem sido designado de várias formas como, por exemplo, o minimizante de percurso agregado (MAT - point of minimum aggregate travel) e as suas propriedades estudadas extensivamente. Uma das mais interessantes é que a função $Z(X, Y)$ não tem derivadas definidas nos pontos $\left(x_{i}, y_{i}\right)$. Webber $(1928)$ utilizou o MAT para elaborar a sua teoria de localização industrial, propondo que as fábricas se localizassem em sítios em que os custos totais de transporte de matérias-primas para a empresa e a distribuição dos produtos pelo mercado fossem minimizados.

Há um dispositivo físico que permite obter uma solução para o problema MAT que se designa por quadro de Varignon. Numa placa rígida na horizontal, fazem-se furos em cada uma das posições $\left(x_{i}, y_{i}\right)$. Em cada furo pendura-se uma corda e suspende-se um peso $w_{i}$. As pontas livres das cordas juntam-se e atam-se por cima da placa, soltando-se o nó (ver figura 6). Ignorando os efeitos do atrito, a posição encontrada pelo nó será o ponto MAT.

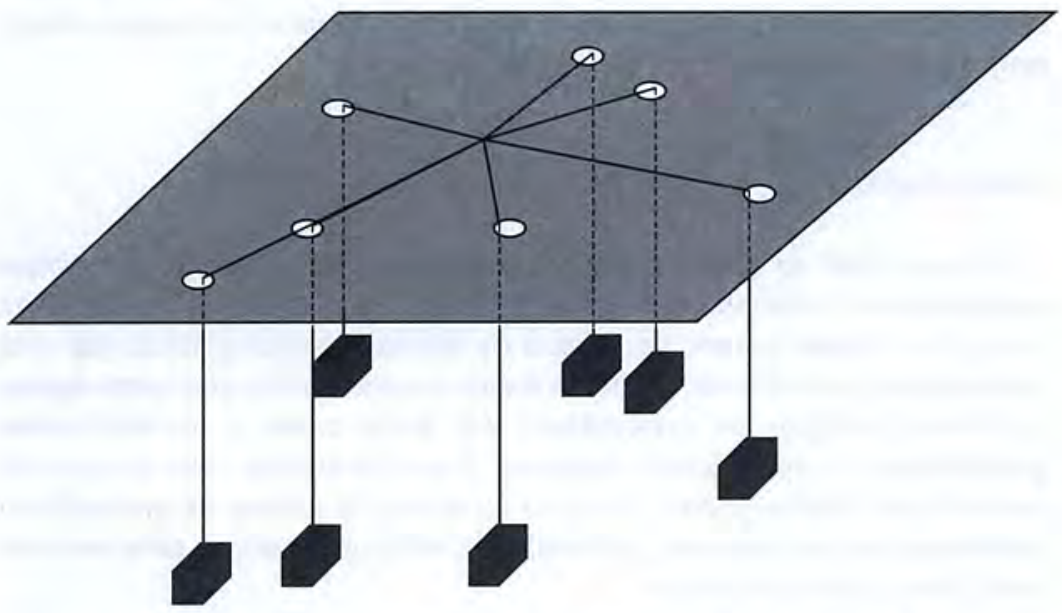

Fig. 6-A experiência do quadro de Varignon. Ver a explicação no texto 
Considere-se agora a seguinte experiência mental. Suponhamos que um peso representa um fornecimento para a fábrica que está localizada de modo óptimo no nó e suponhamos que o abastecimento se esgota. Encontra-se uma nova fonte de abastecimento mais afastada, mas na mesma direcção. Faz-se um novo furo neste local e repete-se a experiência. Será que a localização da fábrica se move? A intuição diz que sim, dado que o ponto MAT minimiza as distâncias e a distância mudou. Mas o quadro de Varignon diz que não, dado que a força que puxa a corda é a mesma independentemente da localização dos furos e todas as outras forças permanecem imutáveis.

A utilização do cálculo diferencial para obter as derivadas de $Z$ a respeito de $X$ e $Y$ mostra que a analogia física está correcta e a intuição errada. A intuição parece mais compatível com as propriedades do centróide, que minimiza a soma pesada dos quadrados das distâncias e se moverá nesta experiência mental, do que com as propriedades do ponto MAT. Propriedades não intuitivas, de algum modo semelhantes, podem ser facilmente encontradas para o caso unidimensional de pontos localizados ao longo de uma linha e para muitas generalizações do problema MAT básico. De maneira geral, parece que a intuição humana é particularmente limitada no que diz respeito a encontrar soluções para problemas de optimização espacial, fazendo assim eco de um ponto levantado anteriormente relativo a problemas estatísticos. À semelhança do que então se referiu, a lição a retirar deste exemplo é que os instrumentos matemáticos são uma ajuda preciosa, que nos permite resolver problemas geográficos de uma forma mais eficaz, assim como projectar soluções mais adequadas.

\section{CONClusão}

Como referi no início, a geografia constitui uma fonte de problemas interessantes e estimulantes para os matemáticos. Como mostram os exemplos, o vasto campo da ciência da informação geográfica, que está em constante crescimento, também fornece novas motivações para alguns problemas antigos de matemática, em áreas como a probabilidade geométrica e a optimização espacial. Estes problemas são de enorme importância prática, assim como do interesse de muitas organizações e indivíduos que se dedicam à aplicação de dados geográficos para resolver problemas e tomar decisões.

Nesta análise tentei evidenciar o que costumo considerar o conflito frequente entre a intuição humana e a lógica matemática relativamente a 
tópicos geográficos. Nós, humanos, trabalhamos constantemente com o espaço. Acreditamos que «uma fotografia vale mais que mil palavras» e que as crianças aprendem a ter capacidades espaciais numa idade tenra. Mas a familiaridade também parece ser uma fonte de falsa segurança porque o que aprendemos sobre o espaço não está necessariamente correcto. Devido a ilusões ópticas e efeitos relacionados, vemos muitas vezes padrões onde não existem; a nossa intuição no que respeita à optimização espacial é nitidamente errónea; falta-nos, muitas vezes, o sentido correcto do que esperar em propriedades topológicas, como, por exemplo, o número médio de arestas por face num mosaico. Actualmente há a noção generalizada da crescente importância da localização geográfica, assim como do pensamento espacial na sociedade moderna. Espero ter conseguido mostrar claramente que esta importância crescente justifica que se dê maior atenção à matemática da geografia.

\section{Referências}

Abrahams, A. D. (1984) - Channel networks: A geomorphological perspective. Water Resources Research 20: 161-188.

Christaller, W. (1966) - The Central Places of Southern Germany, translated by C. W. Baskin. Englewood Cliffs, New Jersey: Prentice-Hall.

Goodchild, M. F., e D. M. Mark (1987) - The fractal nature of geographic phenomena. Annals of the Association of American Geographers 77: 265-278.

Horton, R. E. (1945) - Erosional development of streams and their drainage basins: Hydrophysical approach to quantitative morphology. Geological Society of America Bulletin 56: 275-370.

Mandelbrot, B. B. (1983) - The Fractal Geometry of Nature. São Francisco: Freeman.

Richardson, L. F. (1961) - The problem of contiguity: An appendix to the statistics of deadly quarrels. General Systems Yearbook 6: 139-187.

Shreve, R. L. (1966) - Statistical law of stream numbers. Journal of Geology 74: 17-37.

Shreve, R. L. (1967) - Infinite topologically random channel networks. Journal of Geology 75: 178-186.

Strahler, A. N. (1952) - Hypsometric analysis of erosional topography. Geological Society of America Bulletin 63: 1117-1142.

Weber, A. (1928) - Alfred Weber's Theory of the Location of Industries. Translated by C.J. Friedrich. Chicago: University of Chicago Press. 


\section{$\begin{array}{llllll}\text { C I E } & \mathbf{N} & \mathbf{C} & \mathbf{A}\end{array}$}

mitiram realizar com sucesso tarefas tão distintas como a programação de um voo a Marte, a previsão de resultados eleitorais, a explicação do funcionamento de alguns mecanismos do sistema nervoso, ou a abordagem critica de obras de arte e de textos literários. Da ciência à sociedade, dos grandes avanços técnicos à solidez de uma argumentação lógica, a Matemática constrói teias de uma imensa flexibilidade resultante do carácter universal da sua linguagem.

Neste livro, personalidades de diferentes universos dão o seu testemunho sobre a forma como usam as teias matemáticas para tecer a sua própria visão do mundo.

Maria Paula Serra de Oliveira é professora de Matemática na Faculdade de Ciências e Tecnologia da Universidade de Coimbra. 